\title{
Identification of $\beta$-Glucosidase Activity of Lentilactobacillus buchneri URN103L and Its Potential to Convert Ginsenoside Rb1 from Panax ginseng
}

\author{
Gereltuya Renchinkhand ${ }^{1}\left(\mathbb{D}\right.$, Urgamal Magsar ${ }^{1}$, Hyoung Churl Bae ${ }^{1}$, Suk-Ho Choi ${ }^{2}$ and Myoung Soo Nam ${ }^{1, *}$ \\ 1 Division of Animal Resource Science, Chungnam National University, Daejeon 34134, Korea; \\ handgai@yahoo.com (G.R.); magsarurgamal@gmail.com (U.M.); hcbae@cnu.ac.kr (H.C.B.) \\ 2 Department of Animal Biotechnology, Sangji University, Wonju 26339, Korea; shchoi@sangji.ac.kr \\ * Correspondence: namsoo@cnu.ac.kr; Tel.: +82-42-821-5782
}

check for

updates

Citation: Renchinkhand, G.; Magsar, U.; Bae, H.C.; Choi, S.-H.; Nam, M.S. Identification of $\beta$-Glucosidase Activity of Lentilactobacillus buchneri URN103L and Its Potential to Convert Ginsenoside Rb1 from Panax ginseng. Foods 2022, 11, 529. https:// doi.org/10.3390/foods11040529

Academic Editors: Wojciech

Kolanowski and Anna

Gramza-Michałowska

Received: 10 January 2022

Accepted: 8 February 2022

Published: 12 February 2022

Publisher's Note: MDPI stays neutral with regard to jurisdictional claims in published maps and institutional affiliations.

Copyright: (C) 2022 by the authors. Licensee MDPI, Basel, Switzerland. This article is an open access article distributed under the terms and conditions of the Creative Commons Attribution (CC BY) license (https:// creativecommons.org/licenses/by/ $4.0 /$ )

\begin{abstract}
Lentilactobacillus buchneri isolated from Korean fermented plant foods produces $\beta$-glucosidase, which can hydrolyze ginsenoside Rb1 from Panax ginseng to yield ginsenoside Rd. The aim of this study was to determine the mechanisms underlying the extracellular $\beta$-glucosidase activity obtained from Lentilactobacillus buchneri URN103L. Among the 17 types of lactic acid bacteria showing positive $\beta$-glucosidase activity in the esculin iron agar test, only URN103L was found to exhibit high hydrolytic activity on ginsenoside $\mathrm{Rb} 1$. The strain showed 99\% homology with Lentilactobacillus buchneri NRRLB 30929, whereby it was named Lentilactobacillus buchneri URN103L. Supernatants of selected cultures with $\beta$-glucosidase activity were examined for hydrolysis of the major ginsenoside $\mathrm{Rb} 1$ at $40{ }^{\circ} \mathrm{C}$, $\mathrm{pH}$ 5.0. Furthermore, the $\beta$-glucosidase activity of this strain showed a distinct ability to hydrolyze major ginsenoside Rb1 into minor ginsenosides Rd and Rg3. Lentilactobacillus buchneri URN103L showed higher leucine arylamidase, valine arylamidase, $\alpha$-galactosidass, $\beta$-galactosidase, and $\beta$ glucosidase activities than any other strain. We conclude that $\beta$-glucosidase from Lentilactobacillus buchneri URN103L can effectively hydrolyze ginsenoside Rb1 into Rd and Rg3. The converted ginsenoside can be used in functional foods, yogurts, beverage products, cosmetics, and other health products.
\end{abstract}

Keywords: $\beta$-glucosidase; ginsenoside Rb1; Rd; Rg3; hydrolyze; Lentilactobacillus buchneri URN103L

\section{Introduction}

Korean ginseng (Panax ginseng C.A. Mey) contains approximately 200 substances, including ginsenosides, polysaccharides, polyacetylenes, peptides, and amino acids. To date, 100 ginsenosides have been isolated, with $\mathrm{Rb} 1, \mathrm{Rb} 2, \mathrm{Rc}, \mathrm{Re}$, and $\mathrm{Rg} 1$ constituting more than $80 \%$ of all ginsenosides reported [1,2]. The most abundant components of Korean ginseng are ginsenosides (ginseng saponin) and polysaccharides, which are not absorbed by the human intestines due to their chemical hydrophilicity. However, if these constituents come into contact with the intestinal microbiota in the digestive tract, microbes use them to produce minor metabolites, such as compound K and protopanaxatriol, which are easily absorbed by the human intestines. These metabolites exhibit important pharmacological functions, including antitumor, antidiabetic, anti-inflammatory, anti-allergic, immunomodulatory, and neuroprotective activities [3-5]. Lactic acid bacteria (LAB) are an integral part of traditional food processing and preservation technologies, including the fermentation of dairy products, plants, and meat. The hydrolysis of plant metabolite glucoconjugates by the $\beta$-glucosidase activities of LAB is a significant contribution to the biological activity and dietary attributes of fermented food [6].

Furthermore, LAB exhibiting extracellular $\beta$-glucosidase activity are present in fermented plant foods; indeed, certain LAB strains possessing $\beta$-glucosidase activity may 
have the potential to metabolize ginsenoside $\mathrm{Rb} 1$ from $P$. ginseng. The hydrolysis of ginsenosides to ginsenosides $\mathrm{Rd}$ and $\mathrm{Rg} 3$ by various bacteria can increase their beneficial effects. Therefore, research has been conducted to identify microorganisms that can efficiently metabolize major ginsenosides, e.g., $\mathrm{Rb} 1$ or $\mathrm{Re}$, to minor ginsenosides, e.g., $\mathrm{Rd}$, $\mathrm{F} 2$, compound $\mathrm{K}$, or Rh2 [7]. In addition, ginsenoside Rd can enhance the proliferation of neural stem cells in vivo and in vitro [8] and inhibit the proliferation and survival of gastric and breast cancer cells by influencing the transient receptor potential melastatin 7 (TRPM7) channel [9]. Thus, recently, ginsenoside Rg3 was tested as a new anticancer drug for therapy, in combination with chemotherapy, against lung, gastric, and esophageal cancer in China [10]. Lentilactobacillus buchneri, named in honor of the German bacteriologist E. Buchner, is an obligate heterofermentative facultative anaerobe, described as having diverse effects, such as the prevention of silage spoilage by yeast and molds [11]. Furthermore, buchnericin production by L. buchneri inhibits the growth of some species of Listeria, Bacillus, Micrococcus, Enterococcus, and Vibrio [12]. However, to date, there are no reports on the potential use of the extracellular $\beta$-glucosidase activity of L. buchneri. Therefore, the aim of this study was to determine the extent of ginsenoside Rb1 metabolism to Rd and Rg3 by the extracellular $\beta$-glucosidase activity obtained from L. buchneri URN103L.

\section{Materials and Methods}

\subsection{Isolation of $L A B$ with $\beta$-Glucosidase Activity from Fermented Plants}

Lactobacillus strains were isolated from eight types of traditional Korean fermented plant foods randomly collected from the Daejeon area. Isolation of LAB with $\beta$-glucosidase activity from fermented plants was performed according to the method in [13]. The culture supernatants were filtered using a $0.2 \mu \mathrm{m}$ syringe filter (HYUNDAT MICRO Co. LTD., Seoul, Korea) and mixed with $1 \mathrm{mg} \mathrm{mL}^{-1}$ standard saponin $(\operatorname{Rg} 1(4.80 \%), \operatorname{Re}(12.95 \%)$, $\operatorname{Rc}(11.12 \%), \operatorname{Rd}(5.87 \%), \operatorname{Rb} 2(8.32 \%), \operatorname{Rb} 1(15.91 \%))$ in a $1: 1(v / v)$ ratio. The mixture of supernatant and standard saponin was incubated at $35^{\circ} \mathrm{C}$ for 7 days at $190 \mathrm{rpm}$ in a shaking incubator (Vision Scientific, Korea). The hydrolysis of saponin was monitored by thin-layer chromatography (TLC) analysis.

\section{2. $16 S$ rDNA Sequencing of Strain URN103L}

$16 \mathrm{~S}$ rDNA sequencing of strain URN103L was performed according to the method in [13]. The primers used were 27F:5'-AGAGTTTGATCACTGGCTCAG-3' and 1492R: 5' GGTTACCTTGTTACGACTT-3'. PCR was performed using the $2 \times$ PCR pre Mix (EF-taq) in a GeneAmp PCR system 2700 (Applied Biosystems, Singapore). The NCBI GenBank registration number of strain URN103L is OM438138.1.

\subsection{Identification of Enzyme Activity of the Strain URN103L Using the API ZYM Kit}

Enzyme activity patterns of the selected strains were investigated using the API ZYM Kit for the research of enzymatic activity (bioMerieux, Marcy-I'Etoile, France), following manufacturer instructions [14].

\subsection{Determination of Optimum $\mathrm{pH}$ for $\beta$-Glucosidase Hydrolysis of Ginsenoside Rb1}

L. buchneri URN103L was inoculated in MRS broth at $37^{\circ} \mathrm{C}$ for $24 \mathrm{~h}$, after which the supernatant was collected by centrifugation at $7000 \times \mathrm{g}$ for $15 \mathrm{~min}$ at $4{ }^{\circ} \mathrm{C}$. The crude enzyme extract of the selected cultures was tested for the hydrolysis of major ginsenoside $\mathrm{Rb} 1$ (Daedook Bio, Korea) by $\beta$-glucosidase. The reaction mixture was prepared in a 1:1 $(v / v)$ ratio of supernatant and $0.2 \mathrm{mg} \mathrm{mL}^{-1}$ of ginsenoside $\mathrm{Rb} 1(5 \mathrm{mM}$ of sodium phosphate buffer) and filtered through a $0.2 \mu \mathrm{m}$ syringe filter (HYUNDAT MICRO Co. LTD, South Korea). The reaction mixture was incubated at $35^{\circ} \mathrm{C}$ for 7 days. $\beta$-glucosidase activity of the supernatant was conducted according to the method in [15]. 


\subsection{Determination of Optimum Temperature for $\beta$-Glucosidase Hydrolysis of Ginsenoside Rb1}

The optimum temperature for the hydrolysis of ginsenoside $\mathrm{Rb} 1$ by the crude enzyme extract of L. buchneri URN103L was determined at pH 7.0 at 30, 35, and $40{ }^{\circ} \mathrm{C}$, over 7 days. Then, samples were extracted with butanol (ratio of sample: butanol, 1:1, $(v / v)$ prior to their concentration using a freeze-drying machine (IlshinBioBase, Yangjoo, Korea). Finally, the ginsenoside concentration was adjusted to $1 \mathrm{mg} \mathrm{mL}^{-1}$ for TLC analysis.

\subsection{Thin-Layer Chromatography and High-Performance Liquid Chromatography (HPLC)}

Fermentation characteristics of ginsenosides fermented by the strain L. buchneri URN103L were analyzed by TLC and HPLC, according to the method in [13].

\subsection{Hydrolysis of Ginsenoside Rb1 by L. buchneri URN103L under Optimum Conditions}

The hydrolysis of ginsenoside Rb1 was performed under the optimum conditions determined for $\beta$-glucosidase activity as described above. L. buchneri URN103L was inoculated in MRS broth ( $\mathrm{pH} 7.0$ ), and the crude enzyme extract was collected by centrifugation at $7000 \times g$ for $15 \mathrm{~min}$ at $4{ }^{\circ} \mathrm{C}$. The reaction mixture in ratio $1: 1(v / v)$ of crude enzyme extract ( $\mathrm{pH} 5.0$ ) and $0.2 \mathrm{mg} \mathrm{mL}^{-1}$ of ginsenoside $\mathrm{Rb} 1$ (5 mM of sodium phosphate buffer, $\mathrm{pH} 5.0$ ) was filtered through a $0.2 \mu \mathrm{m}$ syringe filter and incubated at $35^{\circ} \mathrm{C}$ for $3,7,10$, and 14 days. Samples were concentrated using a freeze-drying machine (Ilshin Lab Co., ltd., Korea). Finally, the ginsenoside concentration was adjusted to $1 \mathrm{mg} \mathrm{mL}^{-1}$ for TLC and HPLC.

\subsection{Fermentation Characteristics of a $20 \%$ Ginseng Root Solution Fermented by L. buchneri URN103L}

Ginseng roots were sliced using a mixer for $5 \mathrm{~min}$, diluted to $20 \%$, and sterilized at $75{ }^{\circ} \mathrm{C}$ for $10 \mathrm{~min}$. The resultant $20 \%$ ginseng root solution was incubated with $3 \%$ strain URN103L at $35^{\circ} \mathrm{C}$ for 14 days. After 3, 7, and 14 days, viable cell counts were determined using BCP agar incubated at $37^{\circ} \mathrm{C}$ for $48 \mathrm{~h}$. Fermentation characteristics of ginsenosides fermented by the strain L. buchneri URN103L were analyzed by TLC and HPLC, according to the method in [13].

\subsection{Statistics Analysis}

All experiments were repeated in triplicates. One-way analysis of variance (ANOVA) and Duncan's multiple range tests were conducted using SAS (Statistical Analysis System Institute, Version 9.4, Cary, NC, USA) to measure significant differences $(p<0.05)$. Data are presented as mean \pm standard error.

\section{Results and Discussion}

\subsection{Isolation and Screening of $L A B$ with $\beta$-Glucosidase Activity from Fermented Plants}

Thirty-seven types of pure culture of bacteria from fermented plants were selected in this study. The characteristics of ginsenoside hydrolysis and the utilization of esculin agar for the $\beta$-glucosidase production ability at $37^{\circ} \mathrm{C}$, over $72 \mathrm{~h}$, were carefully investigated. Seventeen strains $(61 \mathrm{~L}, 63 \mathrm{~L}, 64 \mathrm{~L}, 65 \mathrm{~L}, 66 \mathrm{~L}, 67 \mathrm{~L}, 68 \mathrm{~L}, 70 \mathrm{~L}, 71 \mathrm{~L}, 72 \mathrm{~L}, 72 \mathrm{bS}, 73 \mathrm{sS}, 73 \mathrm{bS}, 95 \mathrm{~L}$, $103 \mathrm{~L}, 122$, and 123) among the fermented plant isolates showed an esculin-positive reaction. Furthermore, among these esculin-positive colonies, eight (63L, 65L, 71L, 72S, 73S, 95L, 103L, and 123) showed hydrolysis of ginsenoside Rb1 and were analyzed for 16S rDNA sequencing. Isolated single colonies of strain 103L in BCP and esculin agar are shown in Figure 1. Many researchers have isolated L. buchneri with various biological activities and probiotic properties [16,17]. Indeed, the isolated L. buchneri KU200793 has high $\gamma$ aminobutyric acid (GABA) production ability, and the GABA produced by the isolate was found to have a neuroprotective function and to protect MPP+-stressed SH-SY5Y cells more effectively than other LAB [16]. Further, L. buchneri KU200793 can reportedly be used as a probiotic starter in functional foods to prevent Parkinson's disease [17]. Additionally, L. buchneri P2 isolated from pickled juice has shown probiotic properties, such as cholesterol reduction, bile tolerance, and antimicrobial activity [18]. In this study, we 
isolated L. buchneri URN103L with $\beta$-glucosidase activity that can hydrolyze ginsenoside from ginseng obtained from fermented plants.
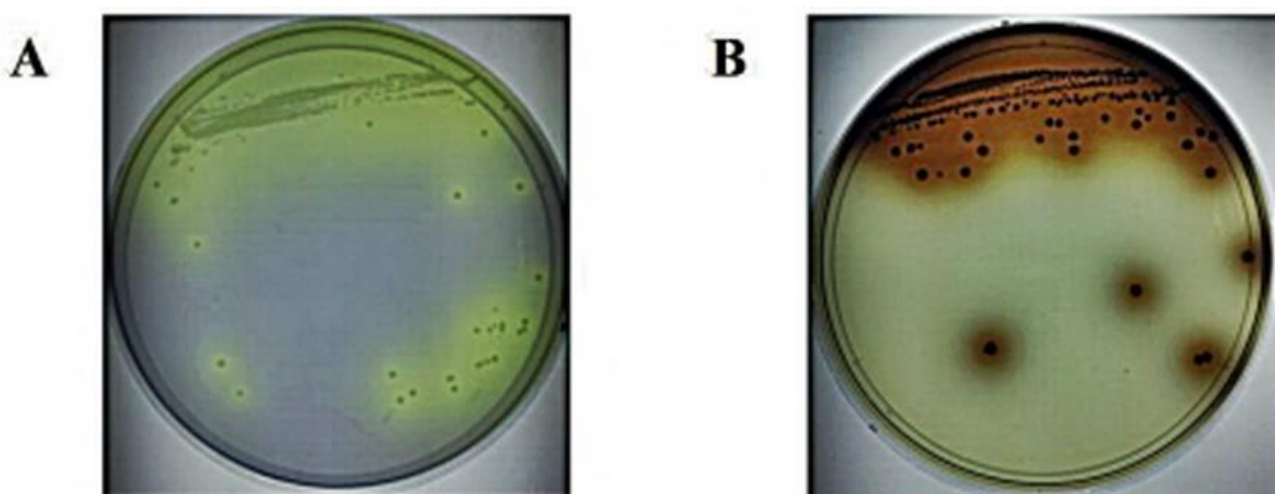

Figure 1. Screening of lactic acid bacteria with $\beta$-glucosidase activity from fermented plants: (A) single colony of strain URN103L in BCP agar, (B) positive reaction of strain. URN103L in esculin agar.

\subsection{Selection of Colonies That Can Hydrolyze Ginsenosides}

Among the selected colonies, strain URN103L actively metabolized major ginsenoside $\mathrm{Rb} 1$ to minor ginsenoside Rd. However, this strain did not metabolize ginsenoside Rb1 to ginsenosides Rb2 and Re. Finally, TLC analysis (Figure 2) showed that LAB showing extracellular $\beta$-glucosidase activity only weakly metabolized ginsenoside Rb1 to ginsenoside $\operatorname{Rd}[13,14]$.

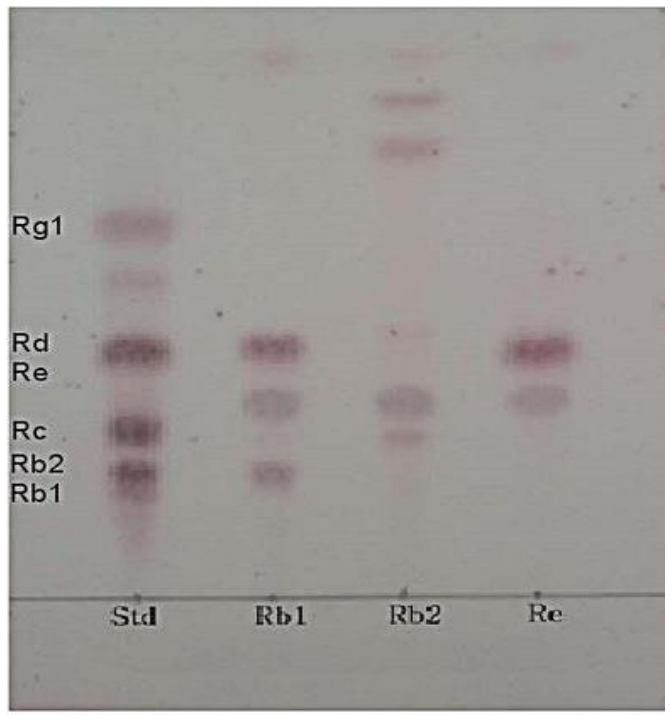

Figure 2. TLC analysis of ginsenosides hydrolyzed by strain URN103L in Rb1, Rb2, and Re for 7 days. Std: standard.

\section{3. $\beta$-Glucosidase Activity of the Selected Strain URN103L}

API ZYM is a simple, rapid system for the detection of bacterial enzymes that allows the detection of enzyme activity on 19 substrates within $4 \mathrm{~h}$ [19]. Among the isolates obtained here, strain URN103L showed the highest level of $\beta$-glucosidase activity. Strain URN103L showed five types of enzymatic activities related to carbohydrate hydrolysis, namely, $\alpha$-galactosidase (4), $\beta$-galactosidase (5), $\beta$-glucuronidase (2), $\alpha$-glucosidase (3), and $\beta$-glucosidase (5). Among LAB isolated from kimchi, L. rhamnosus GG and L. buchneri KU20073 showed the highest level of $\beta$-glucosidase, $\alpha$-glucosidase, and $\beta$-galactosidase activities, which are important enzymes for the hydrolysis of glycosidic linkages [18]. Strain 
URN103L produced four types of proteolytic enzymes, and its activity was similar to that of other LAB. Among these proteolytic enzymes, leucine arylamidase and valine arylamidase showed high activity in the isolated strain URN103L. L. buchneri KU20073 produces leucine arylamidase and valine arylamidase with the highest activity, similar to isolated strain URN103L [17]. Many types of bacteria have been isolated from fermented plants, and their intracellular and extracellular $\beta$-glucosidase activities have been identified [13]. Esculin is a substrate used to quickly screen and identify bacteria with $\beta$-glucosidase activity and is used to add ferrium to bacterial media [20]. Many researchers have studied the $\beta$ glucosidase activity of microorganisms, including L. casei subsp. rhamnosus [21], Leuconostos mesenteroides [22], and Lactobacillus plantarum [23], among LAB species.

\section{4. $16 S$ rDNA Sequencing of Strain URN103L}

Based on the analysis of the $16 \mathrm{~S}$ rDNA sequences, the L. buchneri group is located within the family Lactobacillaceae. This group contained only obligate heterofermentative Lactobacilli. The selected eight types of colonies with an esculin-positive reaction were analyzed by $16 \mathrm{~S}$ rDNA sequencing to determine which species would be matched with strain URN103L, which was selected as the LAB strain among the 14 isolated strains with $\beta$-glucosidase activity. The DNA sequence of strain URN103L was $1474 \mathrm{bp}$, which was compared with the sequences in the NCBI database using BLAST. Phylogenetic trees of strain URN103L were downloaded from the NCBI database and modified in Adobe Illustrator (Figure 3), and they were found to be identical to L. buchneri sp. Indeed, DNA analysis revealed that URN103L showed 99\% homology with the nucleotide sequence of the identified L. buchneri. Therefore, strain URN103L was named L. buchneri URN103L.

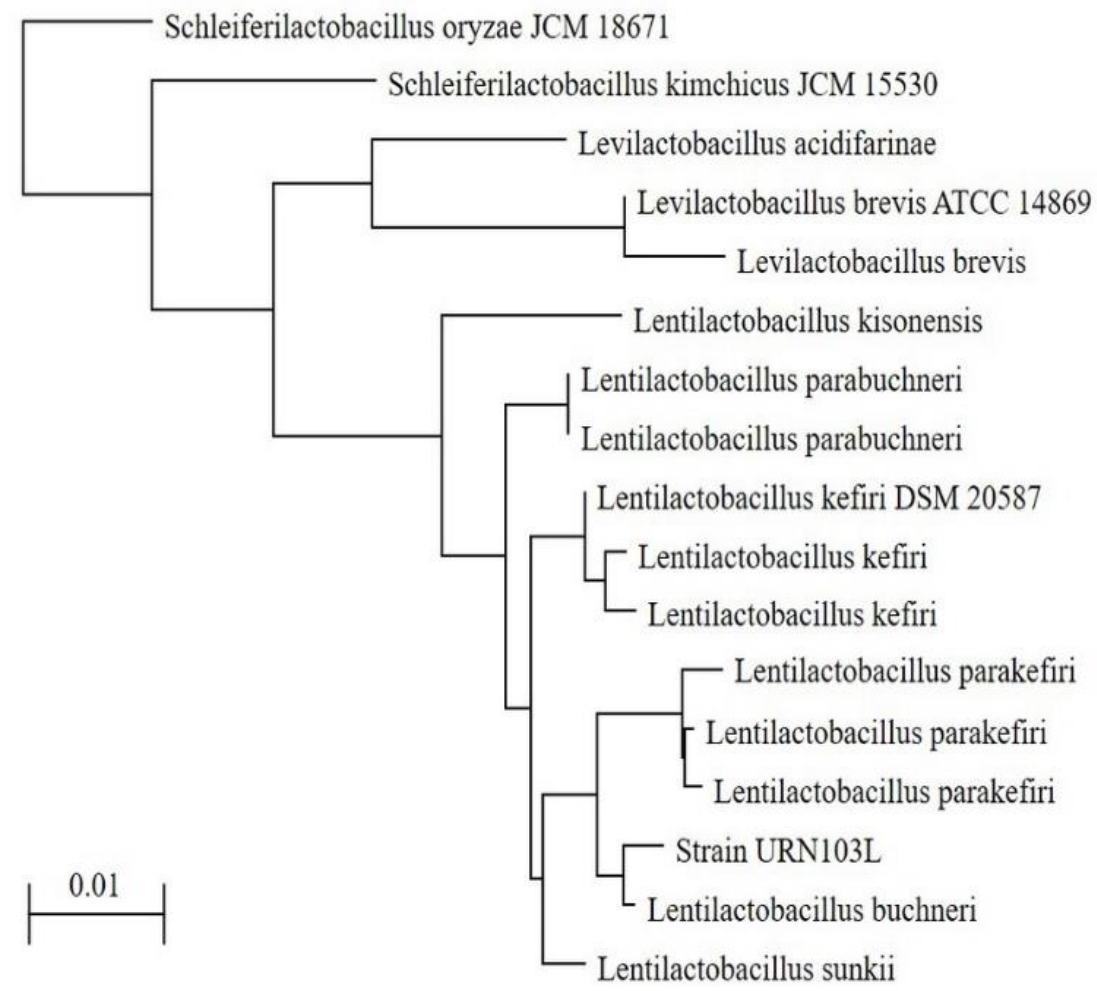

Figure 3. Phylogenetic tree based on $16 \mathrm{~S}$ rDNA sequences. Phylogenetic relationships of strain URN103L with other Lentilactobacillus sp. are shown. Bar (0.01) is scale length.

\subsection{Optimum $p H$ and Temperature of $\beta$-Glucosidase and Conversion of Ginsenoside Rb1}

The optimum $\mathrm{pH}$ and temperature conditions for the activity of the crude enzyme extract were determined to attain the optimum hydrolytic activity for the conversion of ginsenoside $\mathrm{Rb} 1$ to $\mathrm{Rd}$. The optimum $\mathrm{pH}$ for the crude $\beta$-glucosidase extract from L. buchneri URN103L to hydrolyze ginsenoside Rb1 was found to be 5.0 (Figure 4). Different values 
of the optimum $\mathrm{pH}$ have been reported for different species of $\mathrm{LAB}$, such as L. rhamnosus NRRL B442 [24] and L. pentosus strain 6105 [25], for which the corresponding optimum pH was found to be 6.4 and 7.0, respectively. Similarly, to determine the optimum temperature, the hydrolysis temperature of ginsenoside $\mathrm{Rb} 1$ by the crude enzyme extract was adjusted to 30,35 , and $40^{\circ} \mathrm{C}$, at $\mathrm{pH}$ 7.0. As shown in Figure $5,35^{\circ} \mathrm{C}$ was found to be the optimum temperature for the crude $\beta$-glucosidase extract. Based on TLC data analysis (Figures 4 and 5), the optimum conversion conditions were determined to be $\mathrm{pH} 5$ and $35^{\circ} \mathrm{C}$. Ginsenoside $\mathrm{Rb} 1$, which had the weakest band density at $\mathrm{pH} 5$ and $35^{\circ} \mathrm{C}$, was converted to $\mathrm{Rd}$ and $\mathrm{Rg} 3$. The optimum temperature for the $\beta$-glucosidase activity of L. rhamnosus NRRL B442 [26] was reportedly $46^{\circ} \mathrm{C}$. Meanwhile, the optimum temperature of $\beta$-glucosidase isolated from L. pentosus strain 6105 was determined to be $37^{\circ} \mathrm{C}$, using the conversion of ginsenoside $\mathrm{Rb} 1$ to ginsenoside Rd, similar to L. buchneri URN103L [27].

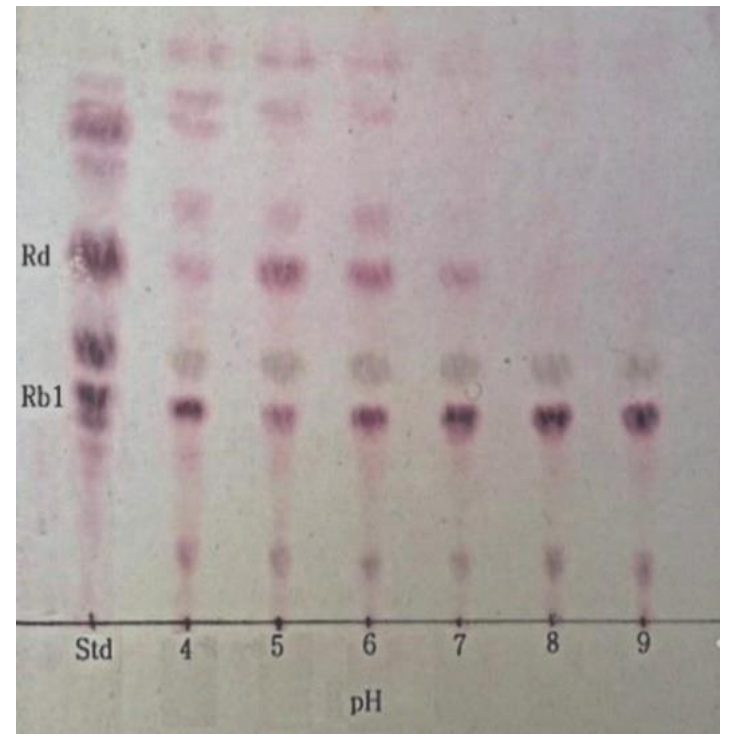

Figure 4. TLC analysis of ginsenoside Rb1 hydrolyzed by crude enzyme of isolated strain URN103L at different $\mathrm{pHs}(4.0,5.0,6.0,7.0,8.0$, and 9.0$)$ at $35^{\circ} \mathrm{C}$ for 7 days.

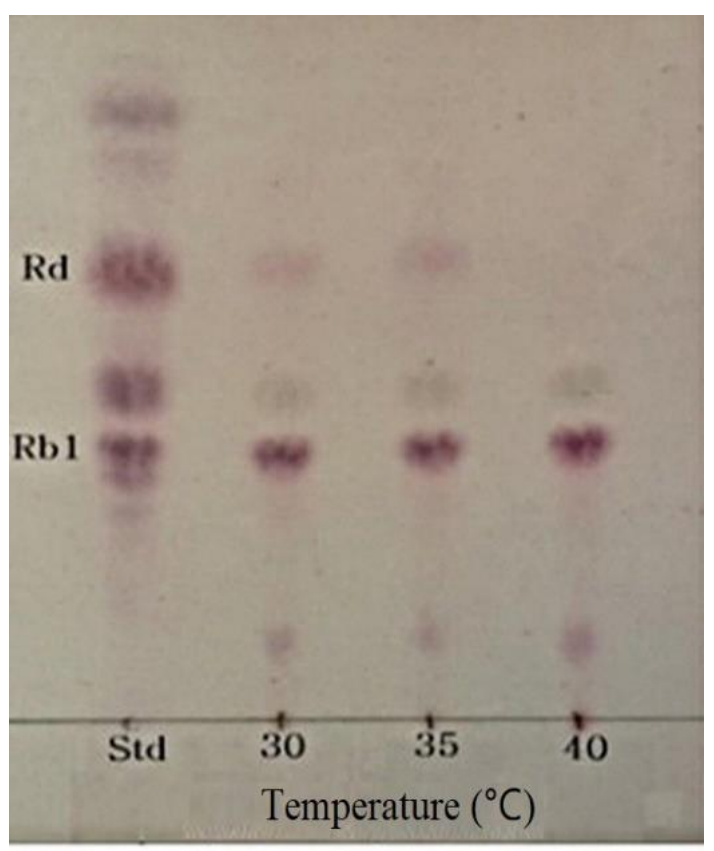

Figure 5. TLC analysis of ginsenoside Rb1 hydrolyzed by crude enzyme of isolated strain URN103L at different temperatures $\left(30,35\right.$, and $\left.40^{\circ} \mathrm{C}\right)$ at $\mathrm{pH} 7.0$ for 7 days. 


\subsection{Metabolism of Ginsenoside Rb1 by $\beta$-Glucosidase Extracted from L. buchneri URN103L}

In this study, under optimal conditions (i.e., $\mathrm{pH} 5.0,35^{\circ} \mathrm{C}$ ), the supernatant of the crude extract containing $\beta$-glucosidase from L. buchneri URN103L converted ginsenoside $\mathrm{Rb} 1$ to ginsenosides $\mathrm{Rd}$ and $\mathrm{Rg} 3$. After 14 days of hydrolysis, ginsenoside Rb1 was fully converted to ginsenoside $\mathrm{Rd}$, and the transformation pathway was from ginsenoside $\mathrm{Rb} 1$ to ginsenoside Rd and then to Rg3, as shown by the results of TLC (Figure 6) and HPLC analysis (Figure 7). Clearly, Rb1 bioconversion increased with the incubation time, as indicated by the disappearance of Rb1 and the increasing intensity of the Rd band. Minor ginsenoside Rg3 was not detected by TLC. However, HPLC analysis (Figure 7) revealed the production of minor ginsenosides $\mathrm{Rd}$ and $\mathrm{Rg} 3$. In the structure of ginsenoside $\mathrm{Rb} 1$ (molecular weight: 1109.29), two glucose molecules are bound to $20-\mathrm{C}$ of the protopanaxadiol ring. Among the two glucose molecules, one glucose molecule is hydrolyzed by $\beta$-glucosidase, and $\mathrm{Rb} 1$ is converted to $\mathrm{Rd}$ (molecular weight: 947.15); then, an additional glucose molecule is hydrolyzed by $\beta$-glucosidase, and Rd is converted to Rg3 (molecular weight: 785.0).

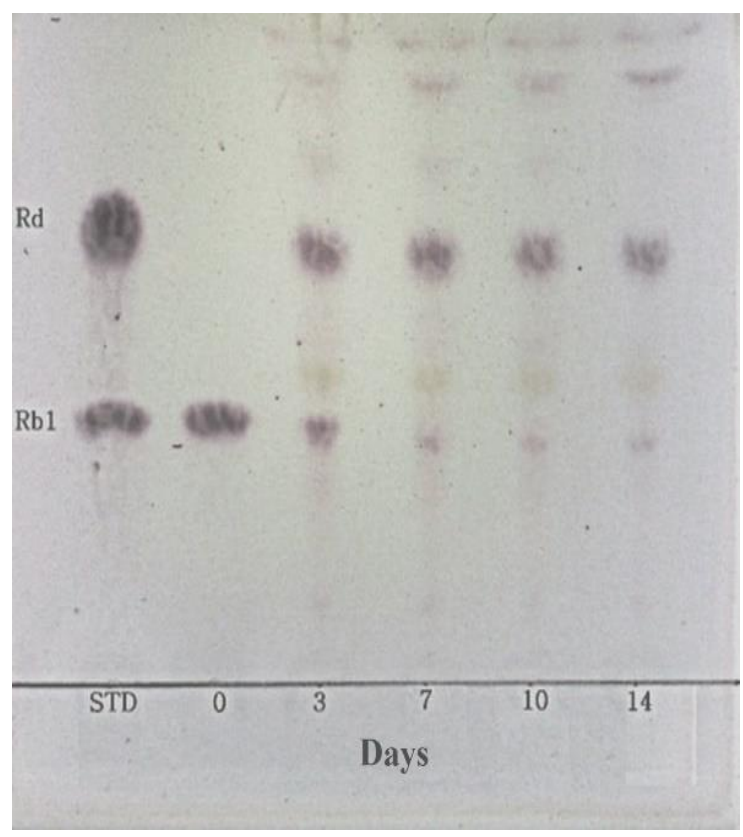

Figure 6. TLC analysis of ginsenoside Rb1 conversion by culture broth of Lentilactobacillus buchneri URN103L under the optimum condition for 14 days of hydrolysis. STD: standard.

Although minor ginsenosides have various beneficial effects, only a small quantity is produced by enzymatic transformation in ginseng. Therefore, many studies have investigated enzymatic transformation methods using various beneficial microorganisms for conversion of major ginsenoside $\mathrm{Rb} 1$. It has been reported that various lactic acid bacteria isolated and identified from kimchi, a traditional Korean fermented food, can perform enzymatic biotransformation of ginsenoside. Leuconostoc mensenteroides WiKim19 and Pediococcus pentosaceus WiKim20 with $\beta$-glucosidase activity isolated from kimchi had a greater ability to transform ginsenoside $\mathrm{Rb} 1$ into ginsenosides $\mathrm{Rg} 3$ and $\mathrm{Rg} 5$ than the other strains [28]. In addition, Lactobacillus plantarum CRNB22 with $\beta$-glucosidase activity isolated from kimchi converted ginsenoside Rb1 into ginsenosides Rg3-s, Rg3-r, and Rg5 [29]. Depending on the enzyme type and experimental conditions, the final conversion of ginsenoside $\mathrm{Rb} 1$ was into $\mathrm{Rd}, \mathrm{Rg} 3$, compound $\mathrm{K}$, and other compounds [26]. Additionally, the crude enzyme extract from Leuconostoc citreum can convert ginsenoside $\mathrm{Rb} 1$ in the following sequence: $\mathrm{Rb} 1 \rightarrow \mathrm{Rd} \rightarrow \mathrm{F} 2 \rightarrow$ compound $\mathrm{K}$ [27]. Consistently, $\beta$-glucosidase isolated from $D$. anomala YAE-1 fully converted ginsenoside $\mathrm{Rb} 1$ to ginsenoside $\mathrm{Rd}$ after 48 $\mathrm{h}$ of incubation [14]. 
$\mathbf{A}$

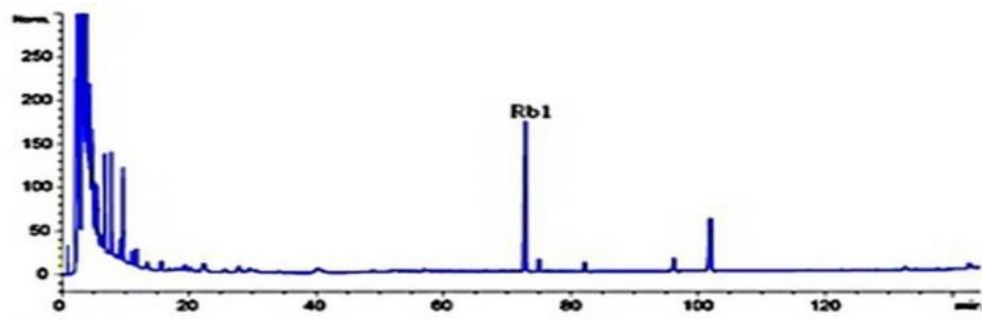

B

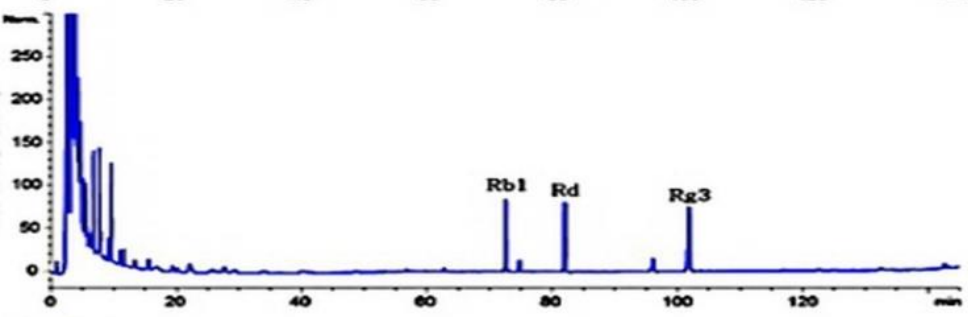

C

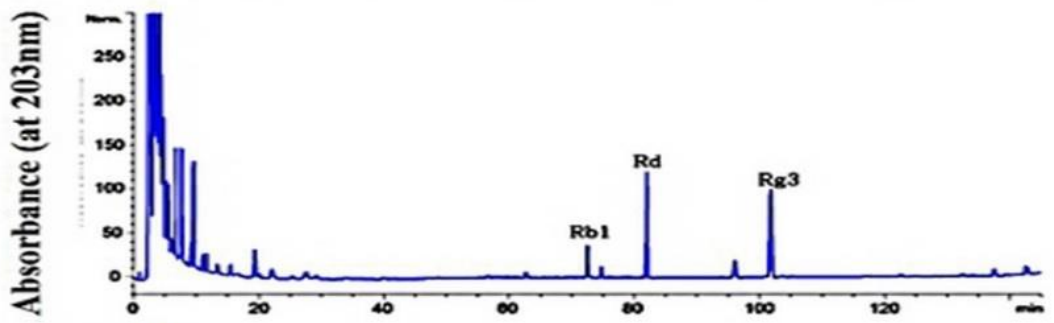

D

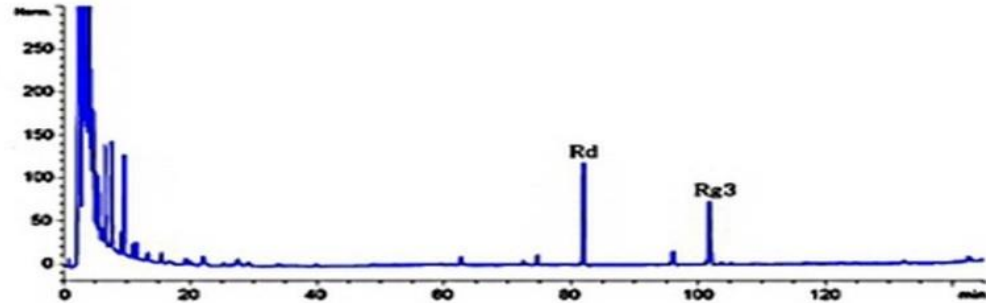

$\mathbf{E}$

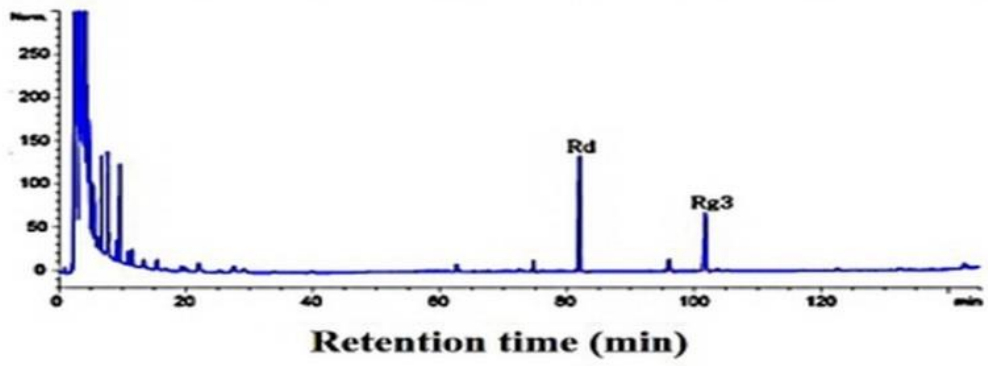

Figure 7. Conversion of ginsenoside Rb1 by crude enzyme from Lactobacillus buchneri URN103L: (A) 0 days; (B) 3 days; (C) 7 days; (D) 10 days; (E) 14 days.

\subsection{Characteristics of the Fermentation of 20\% Ginseng Root Solution by L. buchneri URN103L}

The viable cell count of fermented ginseng roots is shown in Table 1. L. buchneri URN103L was inoculated at 3\%. The initial viable cell count just after inoculation was approximately $6.04 \pm 0.077 \log$ colony-forming unit (CFU) $\mathrm{mL}^{-1}$. After 7 days of fermentation, the viable cell count increased to $8.27 \pm 0.044 \log \mathrm{CFU} \mathrm{mL} \mathrm{m}^{-1}$ and decreased by $7.39 \pm 0.083 \log$ CFU mL ${ }^{-1}$ over 14 days. The six types of LAB in fermented ginseng grew by approximately $9 \sim 11 \log \mathrm{CFU} \mathrm{mL} \mathrm{L}^{-1}$ on the first day, and after 5 days, they decreased to 6.0 7.5 $\log \mathrm{CFU} \mathrm{mL} \mathrm{m}^{-1}$ [2]. Strain L. buchneri URN103L converted major ginsenoside $\mathrm{Rb} 1$ to minor ginsenosides $\mathrm{Rd}$ and $\mathrm{Rg} 3$ (epimer R/S), as shown in Figure 8. TLC analysis showed that the extent of conversion increased with time. Therefore, the growth time was increased to a 14-day period, such that there may be increased production of the enzyme $\beta$-glucosidase. Figure 9A shows the results of fermented Panax ginseng root. When $L$. buchneri URN103L in 20\% ginseng root was incubated, ginsenosides Rb1 and Rd were 
metabolized into Rg3 after 3 days (Figure 9B). Subsequently, after 7 days, ginsenoside Rg3 (S/R) gradually appeared (Figure 9C). As shown in Figure 9D, the resultant minor ginsenosides Rg5, Rd, and Rg3 began to be detected, and their content increased over time. Among the 17 types of LAB exhibiting positive $\beta$-glucosidase activity from fermentation products of Korean plant foods, only 1 (i.e., URN103L) showed high hydrolytic activity on ginsenoside Rb1. The LAB strain was identified as L. buchneri URN103L, which showed 99\% homology with L. buchneri NRRLB 30929. The optimum hydrolysis activity of the $\beta$-glucosidase enzyme on saponin occurred at $35^{\circ} \mathrm{C}$ and $\mathrm{pH}$ 5.0. The identified strain URN103L showed higher $\beta$-glucosidase activities than any other strain. Since ginsenoside $\mathrm{Rb} 1$ itself is not a good growth substrate for Lenti. buchneri, ginsenoside Rb1 was converted using the crude enzyme in culture supernatants. However, since ginseng roots contain a variety of nutrients for the growth of Lenti. buchneri, ginsenoside Rb1 in the ginseng root suspension was converted by fermentation. This study confirms that the $\beta$-glucosidase of L. buchneri URN103L isolated from Korean fermented plant foods can effectively convert ginsenoside $\mathrm{Rb} 1$ into $\mathrm{Rd}$ and $\mathrm{Rg} 3$.

Table 1. Viable cell count of Lentilactobacillus buchneri URN103L after 14 days of fermentation in $20 \%$ ginseng root suspension.

\begin{tabular}{ccccc}
\hline \multirow{2}{*}{$\begin{array}{c}\text { Microorganism } \\
\text { (Log CFU mL }\end{array}$ (1) $^{-1}$} & $\mathbf{0}$ & $\mathbf{3}$ & $\mathbf{7}$ & $\mathbf{1 4}$ \\
\cline { 2 - 5 } & $6.04 \pm 0.08^{\mathrm{d}}$ & $7.88 \pm 0.09^{\mathrm{b}}$ & $8.27 \pm 0.04^{\mathrm{a}}$ & $7.39 \pm 0.08^{\mathrm{c}}$
\end{tabular}

Different superscript letters on each column represent significant differences $(p<0.05)$.

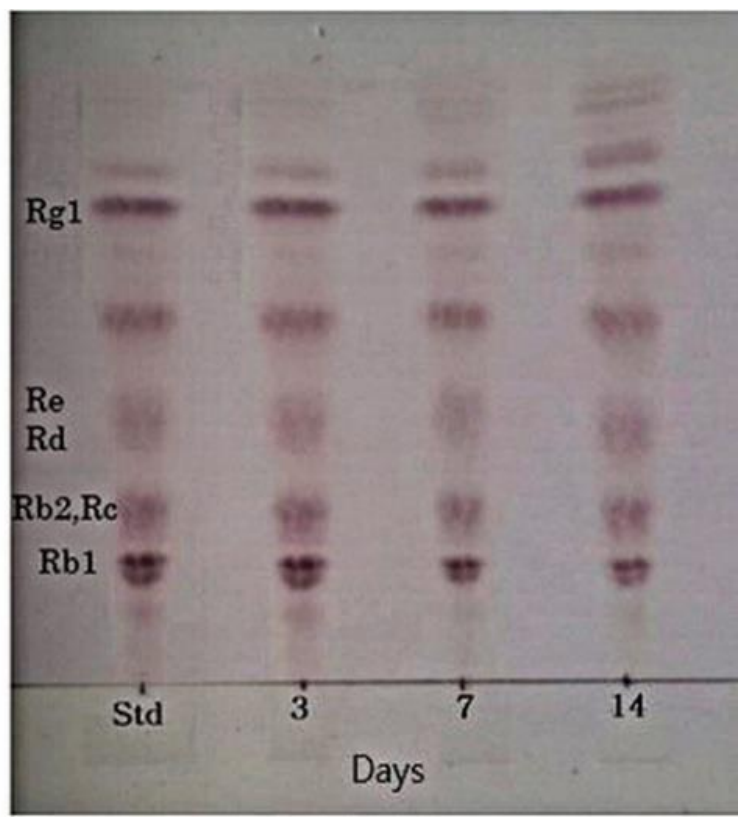

Figure 8. TLC analysis of ginsenoside root conversion by culture broth of Lentilactobacillus buchneri URN103L at optimum condition. Std: standard.

Ginsenoside Rg3, one of the saponins in American ginseng (Panax quinquefolius L. Araliaceae), has been shown to inhibit tumor growth. The most affected pathway of anti-human colorectal cancer activity is the Ephrin receptor pathway in HCT-116 human colorectal cancer cells [30]. In radiation therapy combined with surgery or chemotherapy, Rg3 was applied to inhibit the growth of cancer cells [31]. In addition, there are reports of research on the anticancer activity of ginsenoside $\operatorname{Rg} 3$ in breast cancer [32,33], colon cancer [34,35], gastric cancer [36], lung cancer [37], and liver cancer [38], among others [39]. Ginsenoside $\mathrm{Rd}$ is a biologically active component of ginseng that stimulates the proliferation of endogenous stem cells. Ginsenoside Rd was treated to evaluate its 
effect on gastrointestinal mucosal regeneration with an inflammatory bowel disease (IBD) rat model. [40]. We found that Lentilactobacillus buchneri URN103L with $\beta$-glucosidase activity, isolated from the fermentation of medicinal plants, has the potential to convert ginsenoside $\mathrm{Rb} 1$ into $\mathrm{Rd}$ and $\mathrm{Rg} 3$. In the future, we hope that various biological functions of ginsenosides, such as ginsenoside Rg3, will be revealed and play an important role in human health.

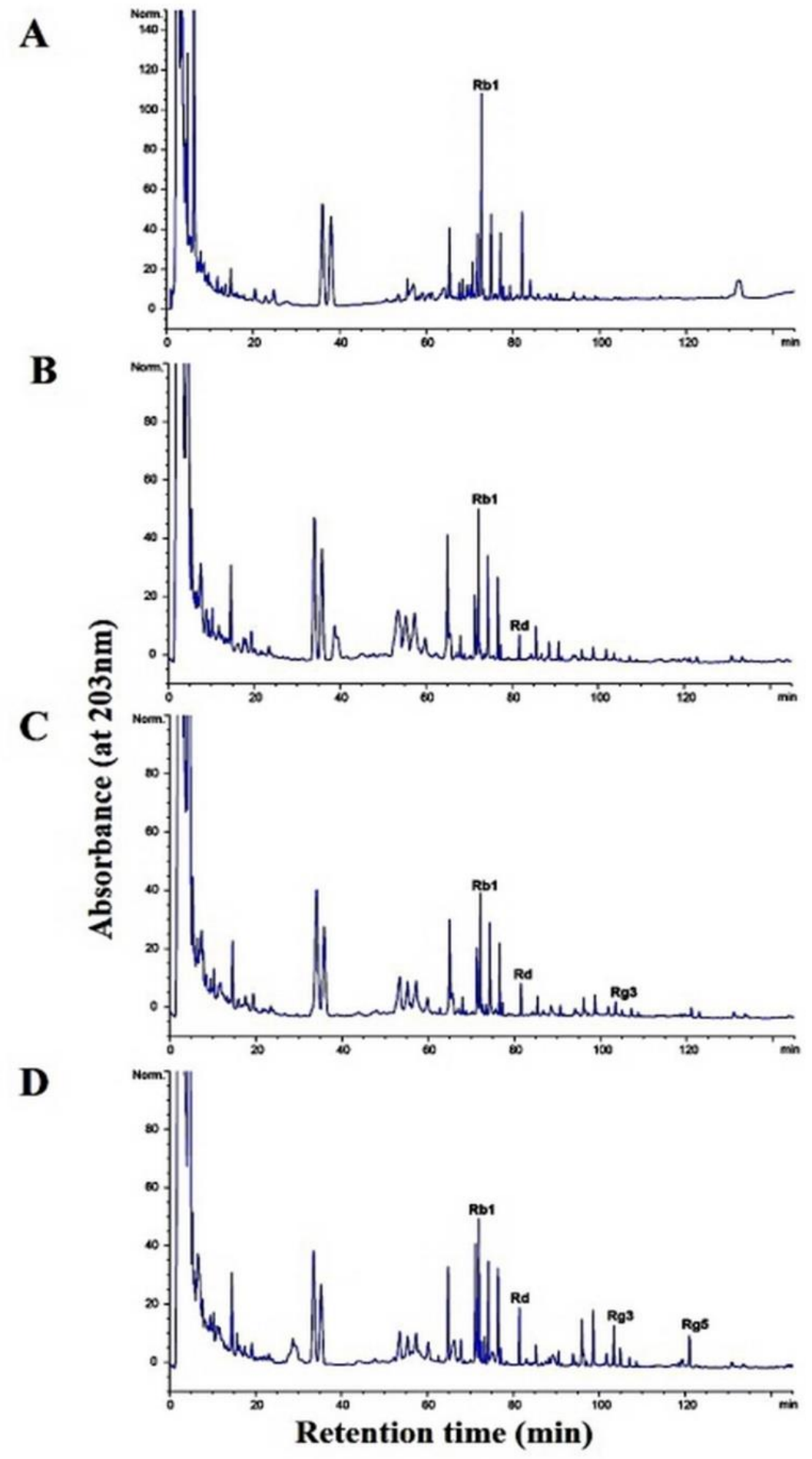

Figure 9. Ginsenoside conversion of ginseng root by Lentilactobacillus buchineri URN103L for fermentation: (A) Panax ginseng root; (B) 3 days; (C) 7 days; (D) 14 days. 


\section{Conclusions}

Among the 17 types of LAB exhibiting positive $\beta$-glucosidase activity from the fermentation products of Korean medicinal plants, only 1 isolate (i.e., URN103L) showed high hydrolytic activity on ginsenoside Rb1. The LAB strain was identified as L. buchneri URN103L, which showed 99\% homology with Lentilactobacillus buchneri NRRLB 30929. The optimum hydrolysis activity of the $\beta$-glucosidase enzyme on saponins occurred at $35^{\circ} \mathrm{C}$ and $\mathrm{pH}$ 5.0. The identified strain URN103L showed higher $\beta$-glucosidase activities than any other strain. This study confirms that the $\beta$-glucosidase of L. buchneri URN103L isolated from Korean fermented medicinal plants can effectively convert ginsenoside Rb1 into $\mathrm{Rd}$ and $\mathrm{Rg} 3$. The converted ginsenoside can be used in the food, cosmetic, and other health product industries.

Author Contributions: Conceived and designed the experiments: G.R., U.M., M.S.N. Performed the experiments: G.R., U.M., H.C.B. Analyzed the data: U.M., H.C.B. Wrote the paper: G.R., U.M., S.-H.C., M.S.N. All authors have read and agreed to the published version of the manuscript.

Funding: This research received no external funding.

Institutional Review Boarding Statement: Not applicable.

Informed Consent Statement: Not applicable.

Data Availability Statement: The datasets used and analyzed in this study are available from the corresponding author on reasonable request.

Acknowledgments: This study was supported in 2021 by research funds from the Institute of Agricultural Science, College of Agriculture and Life Sciences, Chungnam National University (0682-01).

Conflicts of Interest: The authors declare no conflict of interests.

\section{References}

1. Kim, M.W.; Ko, S.R.; Choi, K.J.; Kim, S.C. Distribution of saponin in various sections of Panax ginseng root and changes of its content according to root age. J. Ginseng Res. 1987, 11, 10-16.

2. Park, S.E.; Na, C.S.; Yoo, S.A.; Seo, S.H.; Son, H.S. Biotransformation of major ginsenosides in ginsenoside model culture by lactic acid bacteria. J. Ginseng Res. 2017, 41, 36-42. [CrossRef] [PubMed]

3. Jia, L.; Zhao, Y.; Liang, X.J. Current evaluation of the millennium phytomedicine- ginseng (II): Collected chemical entities, modern pharmacology, and clinical applications emanated from traditional Chinese medicine. Curr. Med. Chem. 2009, 16, $2924-2942$. [CrossRef] [PubMed]

4. $\quad$ Park, J.S.; Shin, J.A.; Jung, J.S.; Hyun, J.W.; Van Le, T.K.; Kim, D.H.; Park, E.M.; Kim, H.S. Anti-inflammatory mechanism of compound $\mathrm{K}$ in activated microglia and its neuroprotective effect on experimental stroke in mice. J. Pharmacol. Exp. Ther. 2012, 341, 59-67. [CrossRef]

5. Radad, K.; Moldzio, R.; Rausch, W.D. Ginsenosides and their CNS targets. CNS. Neurosci. Ther. 2011, 17, 761-768. [CrossRef]

6. Michlmayr, H.; Kneifel, W. beta-Glucosidase activities of lactic acid bacteria: Mechanisms, impact on fermented food and human health. FEMS. Microbiol. Lett. 2014, 352, 1-10. [CrossRef]

7. Chi, H.; Ji, G.E. Transformation of ginsenosides Rb1 and Re from Panax ginseng by food microorganisms. Biotechnol. Lett. 2005, 27, 765-771. [CrossRef]

8. Lin, T.; Liu, Y.; Shi, M.; Liu, X.; Li, L.; Liu, Y.; Zhao, G. Promotive effect of ginsenoside Rd on proliferation of neural stem cells in vivo and in vitro. J. Ethnopharmacol. 2012, 142, 754-761. [CrossRef]

9. Kim, B.J. Involvement of melastatin type transient receptor potential 7 channels in ginsenoside Rd-induced apoptosis in gastric and breast cancer cells. J. Ginseng Res. 2013, 37, 201-209. [CrossRef]

10. Chen, X.J.; Zhang, X.J.; Shui, Y.M.; Wan, J.B.; Gao, J.L. Anticancer Activities of Protopanaxadiol- and Protopanaxatriol-Type Ginsenosides and Their Metabolites. Evid. Based. Complement. Alternat. Med. 2016, 2016, 5738694. [CrossRef]

11. Kleinschmit, D.H.; Schmidt, R.J.; Kung, L., Jr. The effects of various antifungal additives on the fermentation and aerobic stability of corn silage. J. Dairy Sci. 2005, 88, 2130-2139. [CrossRef]

12. Mahdi, L.; Mathkhury, H.J.F.; Kakei, S.; Habeeb, K.; Zwain, L.; Muhammed Ali Salman, I.; Mahdi, N.Z.; Kaabi, S.; Nazar, N. Antibacterial activity of lactobacillus buchneri bacteriocin against vibrio parahaemolyticus. Curr. Appl. Sci. Technol. 2017, 17, 81-86. 
13. Renchinkhand, G.; Cho, S.H.; Urgamal, M.; Park, Y.W.; Nam, J.H.; Bae, H.C.; Song, G.Y.; Nam, M.S. Characterization of Paenibacillus sp. MBT213 Isolated from Raw Milk and Its Ability to Convert Ginsenoside Rb1 into Ginsenoside Rd from Panax ginseng. Korean. J. Food Sci. Anim. Resour. 2017, 37, 735-742. [CrossRef] [PubMed]

14. Renchinkhand, G.; Cho, S.H.; Park, Y.W.; Song, G.Y.; Nam, M.S. Biotransformation of Major Ginsenoside Rb1 to Rd by Dekkera anomala YAE-1 from Mongolian Fermented Milk (Airag). J. Microbiol. Biotechnol. 2020, 30, 1536-1542. [CrossRef] [PubMed]

15. Renchinkhand, G.; Park, Y.W.; Song, G.-Y.; Cho, S.-H.; Urgamal, M.; Bae, H.C.; Choi, J.W.; Nam, M.S. Identification of $\beta$ Glucosidase Activity of Enterococcus Faecalis CRNB-A3 in Airag and Its Potential to Convert Ginsenoside Rb1 from Panax Ginseng. J. Food Biochem. 2016, 40, 120-129. [CrossRef]

16. Cho, Y.R.; Chang, J.Y.; Chang, H.C. Production of gamma-aminobutyric acid (GABA) by Lactobacillus buchneri isolated from kimchi and its neuroprotective effect on neuronal cells. J. Microbiol. Biotechnol. 2007, 17, 104-109.

17. Cheon, M.J.; Lim, S.M.; Lee, N.K.; Paik, H.D. Probiotic Properties and Neuroprotective Effects of Lactobacillus buchneri KU200793 Isolated from Korean Fermented Foods. Int. J. Mol. Sci. 2020, 21, 1227. [CrossRef]

18. Zeng, X.Q.; Pan, D.D.; Guo, Y.X. The probiotic properties of Lactobacillus buchneri P2. J. Appl. Microbiol. 2010, 108, 2059-2066. [CrossRef]

19. Humble, M.W.; King, A.; Phillips, I. API ZYM: A simple rapid system for the detection of bacterial enzymes. J. Clin. Pathol. 1977, 30, 275-277. [CrossRef]

20. Pérez, G.; Fariña, L.; Barquet, M.; Boido, E.; Gaggero, C.; Dellacassa, E.; Carrau, F. A quick screening method to identify $\beta$-glucosidase activity in native wine yeast strains: Application of Esculin Glycerol Agar (EGA) medium. World J. Microbiol. Biotechnol. 2011, 27, 47-55. [CrossRef]

21. Matsuda, S.; Norimoto, F.; Matsumoto, Y.; Ohba, R.; Teramoto, Y.; Ohta, N.; Ueda, S. Solubilization of a novel isoflavone glycoside-hydrolyzing $\beta$-glucosidase from Lactobacillus casei subsp. rhamnosus. J. Ferment. Bioeng. 1994, 77, 439-441. [CrossRef]

22. Gueguen, Y.; Chemardin, P.; Labrot, P.; Arnaud, A.; Galzy, P. Purification and characterization of an intracellular beta-glucosidase from a new strain of Leuconostoc mesenteroides isolated from cassava. J. Appl. Microbiol. 1997, 82, 469-476. [CrossRef]

23. Sestelo, A.B.F.; Poza, M.; Villa, T.G. $\beta$-Glucosidase Activity in a Lactobacillus Plantarum Wine Strain. World. J. Microbiol. Biotechnol. 2004, 20, 633. [CrossRef]

24. Kok, F.S.; Muhamad, I.I.; Lee, C.T.; Razali, F.; Pa'e, N.; Shaharuddin, S. Effects of pH and Temperature on the Growth and $\beta$-Glucosidase Activity of Lactobacillus Rhamnosus NRRL 442 in Anaerobic Fermentation. Int. Rev. Chem. Eng. 2012, 4, 293-299.

25. Kim, S.H.; Min, J.W.; Quan, L.H.; Lee, S.; Yang, D.U.; Yang, D.C. Enzymatic Transformation of Ginsenoside Rb1 by Lactobacillus pentosus Strain 6105 from Kimchi. J. Ginseng Res. 2012, 36, 291-297. [CrossRef] [PubMed]

26. Ko, S.R.; Suzuki, Y.; Suzuki, K.; Choi, K.J.; Cho, B.G. Marked production of ginsenosides Rd, F2, Rg3, and compound K by enzymatic method. Chem. Pharm. Bull. 2007, 55, 1522-1527. [CrossRef]

27. Quan, L.H.; Piao, J.Y.; Min, J.W.; Yang, D.U.; Lee, H.N.; Yang, D.C. Bioconversion of ginsenoside Rb1 into compound k by Leuconostoc citreum LH1 isolated from kimchi. Braz. J. Microbiol. 2011, 42, 1227-1237. [CrossRef]

28. Park, B.; Hwang, H.; Lee, J.; Sohn, S.-O.; Lee, S.H.; Jung, M.Y.; Lim, H.I.; Park, H.W.; Lee, J.-H. Evaluation of ginsenoside bioconversion of lactic acid bacteria isolated from kimchi. J. Ginseng Res. 2017, 41, 524-530. [CrossRef]

29. Identification of $\beta$-Glucosidase Activity of Lactobacillus plantarum CRNB22 in Kimchi and Its Potential to Con vert Ginsenoside $\mathrm{Rb}_{1}$ from Panax Ginseng. J. Food Chem. 2015, 39, 155-163. [CrossRef]

30. Luo, X.; Wang, C.-Z.; Chen, J.; Song, W.-X.; Luo, J.; Tang, N.; He, B.-C.; Kang, Q.; Wang, Y.; Du, W.; et al. Characterization of gene expression regulated by American ginseng and ginsenoside Rg3 in human colorectal cancer cells. Inter. J. Oncol. 2008, 32, 975-983. [CrossRef]

31. Wang, L.; Li, X.; Song, Y.-M.; Wang, B.; Zhang, F.-R.; Yang, R.; Wang, H.-Q.; Zhang, G.-J. Ginsenoside Rg3 sensitizes human non-small cell lung cancer cells to $\gamma$-radiation by targeting the nuclear factor-kB pathway. Mol Med Rep 2015, 27, 609-614 [CrossRef] [PubMed]

32. Kim, B.M.; Kim, D.H.; Park, J.H.; Na, H.K.; Surh, Y.J. GinsenosideRg3 induces apoptosis of human breast cancer (MDA-MB-231) cells. J. Cancer Prev. 2013, 18, 177-185. [CrossRef] [PubMed]

33. Kim, B.M.; Kim, D.H.; Park, J.H.; Surh, Y.J.; Na, H.K. GinsenosideRg3 inhibits constitutive activation of NF- $k B$ signaling in human breast cancer (MDA-MB-231) cells: ERK and Akt as potential upstream targets. J. Cancer Prev. 2014, 19, 23-30. [CrossRef]

34. Yuan, H.D.; Quan, H.Y.; Zhang, Y.; Kim, S.H.; Chung, S.H. 20(S)-ginsenoside Rg3-induced apoptosis in HT-29 colon cancer cells is associated with AMPK signaling pathway. Mol. Med. Rep. 2010, 3, 825-831. [PubMed]

35. Junmin, S.; Hongxiang, L.; Zhen, L.; Chao, Y.; Chaojie, W. Ginsenoside Rg3 inhibits colon cancer cell migration by suppressing nuclear factor kappa B activity. J. Tradit Chin. Med. 2015, 35, 440-444. [CrossRef]

36. Aziz, F.; Wang, X.; Liu, J.; Yan, Q. Ginsenoside Rg3 induces FUT4-mediated apoptosis in H. pylori CagA-treated gastric cancer cells by regulating SP1 and HSF1 expressions. Toxicol. In Vitro 2016, 31, 158-166. [CrossRef]

37. Joo, E.J.; Chun, J.; Ha, Y.W.; Ko, H.J.; Xu, M.Y.; Kim, Y.S. Novel roles of ginsenoside Rg3 in apoptosis through downregulation of epidermal growth factor receptor. Chem. Biol. Interact. 2015, 233, 25-34. [CrossRef]

38. Jiang, J.W.; Chen, X.M.; Chen, X.H.; Zheng, S.S. Ginsenoside Rg3 inhibit hepatocellular carcinoma growth via intrinsic apoptotic pathway. World J. Gastroenterol. 2011, 17, 3605-3613. [CrossRef] 
39. Sun, M.; Ye, Y.; Xiao, L.; Duan, X.; Zhang, Y.; Zhang, H. Anticancer effects of ginsenoside Rg3 (Review). Int. J. Mol. Med. 2017, 39, 507-518. [CrossRef]

40. Yang, N.; Liang, G.; Lin, J.; Zhang, S.; Lin, Q.; Ji, X.; Chen, H.; Li, N.; Jin, S. Ginsenoside Rd therapy improves histological and functional recovery in a rat model of inflammatory bowel disease. Phytother. Res. 2020, 34, 3019-3028. [CrossRef] 